CLINICAL STUDY

\title{
Conventional and novel biomarkers of treatment outcome in patients with acromegaly: discordant results after somatostatin analog treatment compared with surgery
}

Kristine Z Rubeck, Michael Madsen, Caroline Marie Andreasen, Sanne Fisker, Jan Frystyk and Jens Otto L Jørgensen The Medical Research Laboratories, Department of Endocrinology and Internal Medicine, Clinical Institute, Aarhus University Hospital, Nørrebrogade 44, DK-8000 Aarhus C, Denmark

(Correspondence should be addressed to K Z Rubeck; Email: kristinerubeck@dadlnet.dk)

\begin{abstract}
Context: Control of disease activity in acromegaly is critical, but the biochemical definitions remain controversial.

Objective: To compare traditional and novel biomarkers and health status in patients with acromegaly treated with either surgery alone or somatostatin analog (SA).

Design and methods: Sixty-three patients in long-term remission based on normalized total IGF1 levels after surgery alone $(n=36)$ or SA $(n=27)$ were studied in a cross-sectional manner. The groups were comparable at diagnosis regarding demographic and biochemical variables. Each subject underwent $3 \mathrm{~h}$ of serum sampling including a 2-h oral glucose tolerance test (OGTT). Health status was measured by two questionnaires: EuroQoL and Acrostudy (Patient-assessed-Acromegaly symptom questionnaire (PASQ)). Results: Total and bioactive IGF1 ( $\mu \mathrm{g} / \mathrm{l})$ levels were similar (total: $185 \pm 10(\mathrm{SA})$ versus $171 \pm 8$ (surgery) $(P=0.28)$; bioactive: $1.9 \pm 0.2$ vs $1.9 \pm 0.1(P=0.70))$. Suppression of total and free $\mathrm{GH}(\mu \mathrm{g} / \mathrm{l}) \mathrm{during}$ OGTT was blunted in the SA group (total $\mathrm{GH}_{\text {nadir: }} 0.59 \pm 0.08$ (SA) versus $0.34 \pm 0.06$ (surgery) $(P=0.01)$; free $\mathrm{GH}_{\text {nadir: }} 0.43 \pm 0.06$ vs $\left.0.19 \pm 0.04(P<0.01)\right)$. The insulin response to OGTT was delayed, and the $2-\mathrm{h}$ glucose level was elevated during SA treatment $(P=0.02)$. Disease-specific health status was better in patients after surgery $(P=0.02)$.

Conclusions: i) Despite similar and normalized IGF1 levels, SA treatment compared with surgery alone was associated with less suppressed GH levels and less symptom relief; ii) this discordance may be due to specific suppression of hepatic IGF1 production by SA; iii) we suggest that biochemical assessment during SA treatment should include both GH and IGF1.
\end{abstract}

European Journal of Endocrinology 163 717-726

\section{Introduction}

Acromegaly is a rare condition caused by excessive production of $\mathrm{GH}$ usually from a benign pituitary adenoma. The diagnosis is based on clinical symptoms, elevated serum levels of GH and/or insulin-like growth factor 1 (IGF1), and a magnetic resonance imaging (MRI) of the pituitary region. Surgery has stood the test of time as primary therapy, but not all patients are eligible and surgery by itself provides sufficient disease control in only $60 \%$ (1). Medical treatment, in particular slow-release formulations of somatostatin analog (SA), therefore plays an important role. With this treatment, prompt and sustained symptom relief $(2,3)$ as well as functional improvement (4) is usually obtained. In contrast to surgery, it remains to be consistently documented that SA treatment also improves the survival rate, even though two recent meta-analyses indeed point in that direction $(5,6)$.
The biochemical definition of remission or control with either treatment is far from trivial, and no uniform consensus exists (7). Complete restoration of the normal pulsatile GH secretory pattern would be ideal, but this is not feasible in clinical practice. Normalization of IGF1 levels or achievement of a certain nadir GH value, preferably during an oral glucose tolerance test (OGTT), is used in most studies, but the exact definitions of a normal IGF1 level and a nadir GH level vary considerably and depend on the assay and the quality of the reference values (7). Moreover, discordant results of IGF1 and GH levels are frequently observed (8), which may be caused by several factors. GH levels are influenced not only by the disease and its treatment, but also by chronological age, gender, and body composition (9). In addition, slightly elevated GH levels in the presence of normalized IGF1 levels may be an early predictor of disease recurrence (10), but cases of persistent disease despite very low GH levels 
(and elevated IGF1 levels) also exist $(7,11)$. Furthermore, somatostatin acts not only at the pituitary level to suppress GH release, but also exhibits inhibitory effects on GH signaling and thus GH receptor (GHR)-mediated clearance of $\mathrm{GH}$ (12). In addition, somatostatin suppresses insulin secretion (13), which may lower hepatic IGF1 production and hence also the circulating levels of IGF1 (14). It has also been reported that SA treatment may impact the $\mathrm{GH}$ response to oral glucose (8).

In this study, we compared pertinent markers of $\mathrm{GH}$ status in acromegalic patients who were considered in long-term remission based on normalized IGF1 levels either after surgery alone or during SA treatment respectively. This included mean GH curves, nadir GH levels during an OGTT, as well as an assessment of bioactive IGF1 and free GH levels using novel assays. In addition, self-reported health status was assessed in the same patients by means of generic- and disease-specific questionnaires.

\section{Patients and methods}

\section{Patients}

All patients were diagnosed and treated at the neuroendocrine unit of Aarhus University Hospital and were followed on an outpatient basis (Tables 1 and 2). Serum IGF1 measurements were not available before 1989, and pituitary MRI was not a routine practice until 1992. The inclusion criteria were the following: i) clinical remission for $>6$ months at the time of follow-up as defined by IGF1 levels within the normal range for age; ii) treatment with either surgery alone or a slow-release formulation of an SA (i.e. Sandostatin LAR (Novartis) or Lanreotide Autogel (Ipsen, Paris, France)); iii) available serum samples at the time of follow-up. Of the 125 acromegalic patients followed, 62 were excluded from the analysis because of

Table 1 Patient characteristics at baseline. Data are presented as mean \pm S.E.M.

\begin{tabular}{lccc}
\hline & SA treatment & Surgery & $\boldsymbol{P}$ value \\
\hline Number & 27 & 36 & \\
Sex (male/female) & $11 / 16$ & $15 / 21$ & 1.00 \\
Age at diagnosis, years & $44.5 \pm 2.7$ & $47.0 \pm 1.9$ & 0.44 \\
Duration of symptoms & $7.2 \pm 1.2$ & $5.6 \pm 0.8$ & 0.24 \\
$\quad$ (years) & & & \\
Adenoma size & $7 / 17$ & $15 / 21$ & 0.48 \\
$\quad$ (micro/macro) & & & \\
GH nadir $(\mu \mathrm{g} / \mathrm{l})$ & $28.0 \pm 6.9$ & $13.9 \pm 3.0$ & 0.20 \\
IGF1 $(\mu \mathrm{g} / \mathrm{l})$ & $751 \pm 69$ & $724 \pm 49$ & 0.75 \\
Diabetes mellitus & $2 / 25$ & $2 / 34$ & 1.00 \\
$\quad$ (yes/no) & & & \\
Deficiency (\%) & 6 & 3 & 0.43 \\
$\quad$ ACTH (no./total) & $1 / 27$ & $1 / 36$ & \\
TSH (no./total) & $0 / 27$ & $0 / 36$ & \\
FSH/LH (no./total) & $4 / 27$ & $2 / 36$ & \\
\hline
\end{tabular}

Table 2 Patient characteristics at follow-up. Data are presented as mean \pm S.E.M.

\begin{tabular}{lccc}
\hline & SA treatment & Surgery & $\boldsymbol{P}$ value \\
\hline Number & 27 & 36 & \\
Sex (male/female) & $11 / 16$ & $15 / 21$ & 1.00 \\
Age (years) & $58.4 \pm 2.7$ & $58.8 \pm 1.9$ & 0.91 \\
Surgery (yes/no) & $21 / 6$ & $36 / 0$ & \\
Radiation therapy & $2 / 25$ & $1 / 35$ & \\
$\quad$ (yes/no) & & & \\
Time since treatment & $10.7 \pm 1.5$ & $9.9 \pm 1.2$ & 0.64 \\
$\quad$ start (years) & & & \\
Time since surgery & $13.9 \pm 1.8$ & $9.9 \pm 1.2$ & 0.06 \\
$\quad$ (years) & & & \\
Diabetes mellitus & $5 / 22$ & $4 / 32$ & 0.48 \\
$\quad$ (yes/no) & 11 & 11 & 0.82 \\
$\begin{array}{l}\text { Deficiency (\%) } \\
\quad \text { ACTH (no./total) }\end{array}$ & $3 / 27$ & $7 / 36$ & \\
TSH (no./total) & $3 / 27$ & $3 / 36$ & \\
FSH/LH (no./total) & $3 / 27$ & $2 / 36$ & \\
\hline
\end{tabular}

i) treatment with pegvisomant $(n=8)$; ii) being recently diagnosed $(n=10)$; iii) lack of available serum samples for analysis $(n=7)$; 4) non-normalized IGF1 levels $(n=37)$.

Sixty-three patients $(37 \mathrm{~F} / 26 \mathrm{M}$, mean \pm s.E.M. age $59 \pm 2$ years) were included, of whom 36 had been treated with surgery alone (surgery) and 27 were on current treatment with SA. The patients were diagnosed between 1967 and 2008 at a mean age of $45.9 \pm 1.6$ years (Table 1 ). Twenty-one patients in the SA group had initially undergone transsphenoidal surgery. All operations after $1987(n=54)$ were performed by two dedicated neurosurgeons. The mean duration of SA treatment was $10.7 \pm 1.4$ years (range: 0.6-23 years). Three patients had received conventional radiation therapy 2 years after surgery (one in the surgery group and two in the SA group). Eighteen patients received Sandostatin LAR (mean dose: $19 \pm 2 \mathrm{mg} / 4$ weeks), and nine patients were treated with Lanreotide Autogel (mean dose: $66 \pm 4 \mathrm{mg} / 4$ weeks). Twenty-seven of 37 female patients were considered postmenopausal at the time of follow-up based on either retrievable gonadotropin measurements or chronological age ( $>55$ years); four female patients received oral estrogen treatment. At the time of followup, nine patients (SA: 5 and surgery: 4) were diagnosed with type 2 diabetes, of whom one received insulin treatment (SA treatment).

\section{Methods}

The follow-up was performed between 2005 and 2009. The patients were studied after an overnight hospital stay in the fasting and supine state. Blood was sampled from an antecubital vein for $3 \mathrm{~h}$ at 10-min intervals for the first hour ('spontaneous profile') after which an oral glucose load $(75 \mathrm{~g})$ was given $(t=0)$ followed by sampling at $t=30,45,60,90$, and $120 \mathrm{~min}$. The standard measurements included total GH in all 
samples, a single total IGF1, and blood glucose during the OGTT. For the purpose of this study, free $\mathrm{GH}, \mathrm{GH}$ binding protein (GHBP), bioactive IGF1, IGF-binding protein (IGFBP)-1, -2, -3 , and insulin were measured from serum samples stored at $-20{ }^{\circ} \mathrm{C}$ (mean storage time: $13 \pm 1$ months).

\section{Assays}

Total IGF1 levels were measured by a validated, in-house time-resolved immunofluorometric assay (TR-IFMA) after acid-ethanol extraction of the IGFBPs, using recombinant human (rh) IGF1 as standard (Austral Biologicals, San Ramon, CA, USA). Intra- and inter-assay coefficient of variation $(\mathrm{CV})$ averaged 5 and $10 \%$ respectively (15). Bioactive IGF1 was determined by a cell-based kinase receptor activation assay (KIRA) based on human embryonic cells transfected with the human IGF1 receptor (IGF1R) gene (16). The bioassay determines the ability of serum IGF to phosphorylate the IGF1R in vitro, and takes into account the presence of the IGFBPs and their ability to modify IGF1R activation. The signal obtained in serum was compared to a serial dilution of rh IGF1 (same as in the IGF1 TR-IFMA). As in in vivo, the bioassay detects IGF2- and pro-IGF2mediated activation of the IGF1R with a cross-reactivity of 12 and $2 \%$ respectively, whereas insulin and its analogs barely cross react $(<1 \%)$. Mean intra- and inter-assay CV of the KIRA averaged 10 and 15\% respectively (16). IGFBP1 was determined by an in-house RIA using an MAB that recognizes all phosphoforms of IGFBP1 (MAB 6303, Medix Biochemica, Kauniainen, Finland). The IGFBP1 was calibrated against highly purified amnion IGFBP1 (HyTest Ltd, Turku, Finland) and had intra- and inter-assay CV values averaging 5 and 12\% respectively (17). IGFBP2 was determined by a validated in-house TR-IFMA, based on commercial reagents from R\&D Systems (Abingdon, UK). Intra- and inter-assay CV of the IGFBP2 assayed averaged 5 and $12 \%$ respectively (17). IGFBP 3 was determined by a commercial IRMA (BioSource Inc., Nivelle, Belgium) according to the instructions by the manufacturer. For all data on IGF1, bioactive IGF1, and IGFBP1 to -3 , the obtained measurements were within the operational range of the respective assays.

Circulating $\mathrm{GH}$ levels were measured using a commercial 22 kDa-specific GH TR-IFMA (Delfia, Perkin Elmer Life Sciences, Turku, Finland), calibrated against the international standard WHO 80/505. Total GH was measured in unprocessed serum according to the recommendations from the manufacturer, with one exception: to reduce the impact of GHBP on the readings of the assay, all samples were incubated overnight rather than for $2 \mathrm{~h}$ (18). Free GH levels, i.e. GH not associated with GHBP (identical to the truncated, extracellular domain of the GHR), were determined by a novel, validated in-house ultrafiltration assay that allows separation of free from bound GH at approached in vivo-like conditions. The separation procedure was performed as described recently (18). The obtained ultrafiltrates were assayed for GH using the GH Delfia, performed according to the instructions by the manufacturer, with overall intra- and inter-assay CV values averaging 7 and 11\% respectively, i.e. slightly higher than the corresponding $\mathrm{CV}$ values of total $\mathrm{GH}$. The detection limit of the $\mathrm{GH}$ assay was $0.033 \mu \mathrm{g} / \mathrm{l}(18)$. GHBP was determined by an in-house TR-IFMA with intra- and inter-assay CV values averaging 5 and 12\% respectively (19). Glucose was determined by the glucose oxidase method, and insulin was determined by a commercial TR-IFMA (Delfia, Perkin Elmer Life Sciences).

\section{Health status}

The generic EuroQoL/EQ-5D health questionnaire evaluates general health status and consists of two parts. The first part comprises five questions regarding mobility, self-care, usual activities, pain/discomfort, and anxiety/depression. Each answer corresponds to either no problems (1 point), some problems (2 points) or extreme problems ( 3 points). The second part is a rating scale from 0 to 100 evaluating general health status, where 100 represents the best possible state. The disease-specific questionnaire PASQ from Acrostudy consists of six questions rating $0-8$ yielding a maximum of 48 points, and a seventh question based on the first six questions evaluating overall health status rating 0-10. The first six questions evaluate disease-specific symptoms including headache, excessive sweating, joint pain, fatigue, soft tissue swelling, and numbness and tingling of the extremities. In this questionnaire, a score of 0 to the first six questions indicates no symptoms; likewise, in the overall health status, 0 is the best possible. Fifty-seven patients completed the questionnaires, of whom 55 were eligible for the analysis. Eight patients (four from each group) did not contribute any data.

\section{Ethics}

The protocol had the consent of the Danish Ethical Committee of Region Midtjylland, and was also registered with the Danish Data Protection Agency.

\section{Statistical analysis}

Data were expressed as means \pm s.E.M. Student's $t$-test was performed when data were normally distributed. Otherwise a non-parametric Mann-Whitney rank sum test was used. The $\chi^{2}$-test was performed to compare categorical variables. Area under the curve (AUC) during the OGTT was calculated for total $\mathrm{GH}$, free $\mathrm{GH}$, glucose, and insulin using the trapezoid rule (SigmaPlot 11). The levels of insulin, glucose, total GH, and free $\mathrm{GH}$ during the OGTT were evaluated according to treatment group by two-way ANOVA. Levels of IGF1 were 
correlated to $\log _{10}$-transformed GH data using Pearson's correlation analysis. Multiple linear regression analysis was performed to evaluate predictors of IGF1 levels in women at follow-up. The Statistical software SigmaPlot 11 (Systat Software Inc., San Jose, CA, USA) and SPSS 17.0 (SPSS Inc., Chicago, IL, USA) were employed. A $P$ value $<0.05$ was considered statistically significant.

\section{Results}

\section{Patient characteristics}

Patient characteristics at baseline and follow-up are provided in Tables 1 and 2 respectively. We recorded no differences in pertinent clinical variables between the groups at either time of diagnosis or follow-up. When comparing time since surgery for the two groups, the difference approached statistical significance $(P=0.06)$, but the time since surgery (in the surgery only group) versus the time since start of SA treatment did not differ $(P=0.64)$.

\section{Total and free GH levels}

Total $\mathrm{GH}\left(\mathrm{GH}_{\text {total }}\right)$ levels $(\mu \mathrm{g} / \mathrm{l})$ were comparable in the two groups in the fasting condition $(1.3 \pm 0.2$ (SA) versus $1.2 \pm 0.2$ (surgery), $P=0.53$; Table 3 and Figs 1-3). The nadir level of $\mathrm{GH}_{\text {total }}$ during the OGTT, however, was lower after surgery as compared with SA treatment, and the same difference was recorded in the mean levels of $\mathrm{GH}_{\text {total }}$ during the OGTT (0-120 min) $(0.92 \pm 0.13(\mathrm{SA})$ versus $0.58 \pm 0.07$ (surgery) $(P=0.04))$.

Table 3 Summary of results presented as mean \pm S.E.M.

\begin{tabular}{|c|c|c|c|}
\hline & $\begin{array}{c}\mathrm{SA} \\
\text { treatment }\end{array}$ & Surgery & $P$ value \\
\hline \multicolumn{4}{|l|}{ Total GH (g/l) } \\
\hline Nadir & $0.59 \pm 0.08$ & $0.34 \pm 0.06$ & 0.01 \\
\hline Mean & $1.12 \pm 0.15$ & $0.89 \pm 0.13$ & 0.26 \\
\hline Decrease, mean-nadir (\%) & $43.0 \pm 4.7$ & $59.9 \pm 4.9$ & 0.01 \\
\hline \multicolumn{4}{|l|}{ Free $\mathrm{GH}(\mu \mathrm{g} / \mathrm{l})$} \\
\hline Nadir & $0.43 \pm 0.06$ & $0.19 \pm 0.04$ & 0.002 \\
\hline Mean & $0.57 \pm 0.08$ & $0.36 \pm 0.04$ & 0.04 \\
\hline Decrease, mean-nadir (\%) & $31.7 \pm 4.4$ & $57.9 \pm 5.1$ & 0.001 \\
\hline IGF1 ( $\mu \mathrm{g} / \mathrm{l})$ & $185 \pm 9.7$ & $171 \pm 8.1$ & 0.28 \\
\hline Bioactive IGF1 $(\mu \mathrm{g} / \mathrm{l})$ & $1.9 \pm 0.2$ & $1.9 \pm 0.1$ & 0.70 \\
\hline GHBP (nmol/l) & $1.5 \pm 0.1$ & $1.6 \pm 0.1$ & 0.44 \\
\hline IGFBP1 $(\mu \mathrm{g} / \mathrm{l})$ & $66.3 \pm 6.5$ & $61.8 \pm 6.2$ & 0.46 \\
\hline IGFBP2 ( $\mu \mathrm{g} / \mathrm{I})$ & $315 \pm 31$ & $328 \pm 39$ & 0.86 \\
\hline IGFBP3 $(\mu \mathrm{g} / \mathrm{l})$ & $3852 \pm 141$ & $3764 \pm 98$ & 0.60 \\
\hline GH:IGF1 ratio $(\times 100)$ & $0.3 \pm 0.05$ & $0.2 \pm 0.04$ & 0.02 \\
\hline \multicolumn{4}{|l|}{ Glucose $(\mathrm{mmol} / \mathrm{l})$} \\
\hline FPG & $5.4 \pm 0.2$ & $4.9 \pm 0.1$ & 0.01 \\
\hline $2 \mathrm{~h} \mathrm{glc}$ & $8.5 \pm 0.7$ & $6.8 \pm 0.5$ & 0.02 \\
\hline AUC during OGTT (area) & $1112 \pm 46$ & $902 \pm 48$ & $<0.001$ \\
\hline \multicolumn{4}{|l|}{ Insulin } \\
\hline$C_{\max }(\mathrm{pmol} / \mathrm{l})$ & $281 \pm 39$ & $241 \pm 31$ & 0.28 \\
\hline$T_{\max }(\min )$ & $88 \pm 5.4$ & $66 \pm 4.7$ & 0.004 \\
\hline AUC during OGTT (area) & $18158 \pm 2287$ & $17879 \pm 2488$ & 0.84 \\
\hline
\end{tabular}

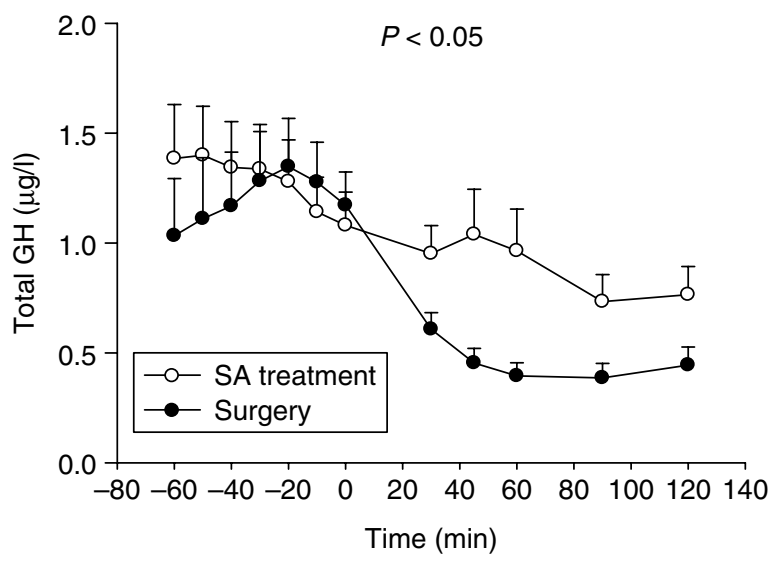

Figure 1 Total serum GH levels (mean \pm S.E.M.) before and during the OGTT (0-120 $\mathrm{min})$. The oral glucose load $(75 \mathrm{~g})$ is given at time 0 .

The relative decrease in $\mathrm{GH}_{\text {total }}$ (\%) during the OGTT was also more pronounced in the surgery group $(43.0 \pm 4.7$ vs $59.9 \pm 4.9(P=0.01))$. This pattern was also evident when comparing the changes in GH levels with time and treatment by means of ANOVA $(P=0.045$; Fig. 1).

The levels of free $\mathrm{GH}\left(\mathrm{GH}_{\text {free }}\right)$ during the OGTT (0-120 min) showed responses similar to $\mathrm{GH}_{\text {total }}$ in both the treatment groups, with a more pronounced suppression after surgery $(P<0.001$; Fig. 2$)$. During the OGTT, both nadir $\mathrm{GH}_{\text {free }}$ and mean $\mathrm{GH}_{\text {free }}$ were higher in the SA group (Fig. 3B). Moreover, the ratio of free to total nadir GH was higher in the SA group $(0.66 \pm 0.04$ (SA) versus $0.50 \pm 0.04$ (surgery), $P=0.02$ ).

Females had higher levels of $\mathrm{GH}_{\text {total }}(\mu \mathrm{g} / \mathrm{l})$ irrespective of treatment as compared with males $(0.57 \pm 0.07$ vs $0.27 \pm 0.05(P=0.01))$, despite similar levels of IGF1 $(\mu \mathrm{g} / \mathrm{l}) \quad(174 \pm 9$ vs $181 \pm 9, \quad(P=0.57)) \quad($ Fig. 4$)$. Among the female patients, we could not detect a significant effect of estrogen status on either nadir $\mathrm{GH}_{\text {total }}$ or IGF1 levels $(\mathrm{GH}(\mu \mathrm{g} / \mathrm{l}): 0.56 \pm 0.09$ (deplete) versus $0.58 \pm 0.13$ (replete), $(P=0.93)$; IGF1 $(\mu \mathrm{g} / \mathrm{l})$ : $163 \pm 7$ (deplete) versus $201 \pm 23$ (replete), $(P=0.07)$ ), and the gender difference in nadir $\mathrm{GH}_{\text {total }}$ also did not depend on the estrogen status of the female patients (data not shown). Multiple linear regression analysis was performed with IGF1 as dependent variable, and treatment modality, age, estrogen status and nadir $\mathrm{GH}_{\text {total }}$ as independent variables. Only age appeared to be a significant and negative predictor of IGF1 $(P=0.012)$.

\section{IGF1, bioactive IGF1, and GH:IGF1 ratio}

As expected, no difference was found between the treatment groups regarding IGF1 levels $(P=0.28$; Table 3 and Figs 3 and 5). Likewise, bioactive IGF1 levels were identical in the two groups. The ratio between nadir $\mathrm{GH}_{\text {total }}$ and total IGF1 was significantly 


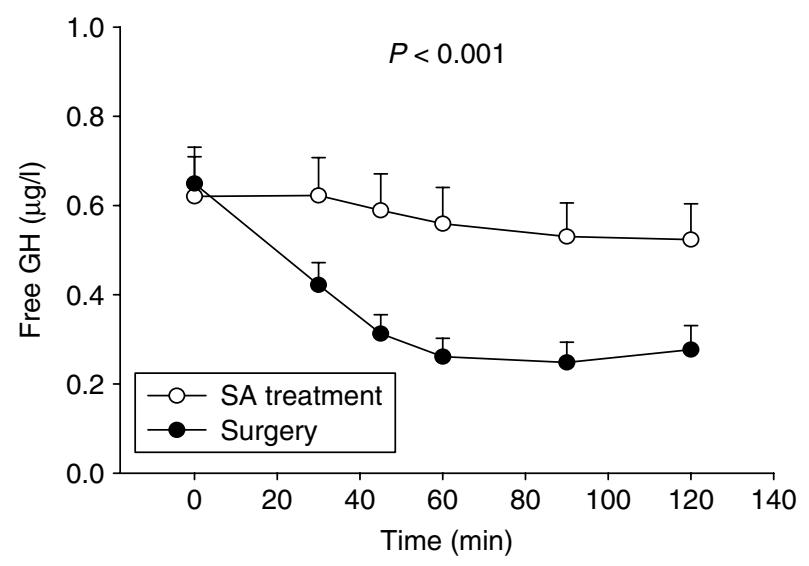

Figure 2 Free serum GH levels (mean \pm s.E.M.) during the OGTT (0-120 min). The oral glucose load is given at time 0 .

higher in the SA group compared with the surgery group $(P=0.02$; Fig. 3$)$.

At baseline levels, $\log \left(\right.$ nadir $\left.\mathrm{GH}_{\text {total }}\right)$ was positively correlated to IGF1 level (all: $r=0.605, P<0.001$; SA: $r=0.631, P=0.007$; surgery: $r=0.619, P<0.001$ ), whereas at follow-up, a significant correlation was found only in the surgery group (Fig. 5) (SA: $r=-0.20$, $P=0.32$; surgery: $r=0.39, P=0.02$ ). The same pattern was observed for $\log$ (nadir $\mathrm{GH}_{\text {free }}$ ) versus bioactive IGF 1 (Fig. 5C and D).

\section{GH- and IGFBPS}

Serum levels of GHBP and IGFBP1, -2 , and -3 were identical in the two groups. Nadir $\mathrm{GH}_{\text {free }}$ levels were negatively correlated to GHBP levels $(r=-0.35$, $P=0.005$; Table 3 ). Total IGF1 levels were negatively correlated to IGFBP $1 \quad(r=-0.25, P=0.046)$ and positively to IGFBP $3(r=0.43, P<0.001)$. In neither operated nor SA-treated patients, we observed correlations between bioactive IGF1 and the molar ratio of IGF1 to IGFBP3 $(r<0.06, P>0.80)$.

\section{Glucose tolerance and insulin secretion}

Glucose levels during the OGTT (fasting, $2 \mathrm{~h}$, and AUC) were more elevated in the SA group (Table 3). The peak insulin concentration measured during the OGTT $\left(C_{\max }\right)$ did not differ significantly between the two groups, but the peak was significantly delayed $\left(T_{\max }\right)$ in the SA group $(P=0.004)$. The AUC for insulin during the OGTT did not differ between the two groups $(P=0.84)$.

\section{Health status}

The general health status assessed by the EuroQoL/EQ5D health questionnaire did not differ between the two groups (Table 4). By contrast, the disease-specific health status (PASQ) was significantly reduced in the SA-treated patients.

\section{Discussion}

This study was undertaken to compare novel and conventional biomarkers of treatment outcome in acromegalic patients with normalized IGF1 levels after surgery alone versus SA treatment. Moreover, selfreported health status was also assessed by means of generic as well as disease-specific questionnaires. Our main finding is that patients treated with SA exhibit elevated nadir GH levels as compared with patients treated with surgery alone. This was associated with a reduced disease-specific health status in patients treated with SA.

Our study design has limitations. First, the study was not randomized, so even though the two groups did not differ significantly at the time of diagnosis with regard to demographic variables and disease activity, the majority of patients on SA treatment were by definition selected on the basis that they had not responded successfully to initial surgery. In this regard, it is worth noting that the SA group exhibited numerically higher GH levels at the time of diagnosis, although it did not reach statistical significance. We could not record a difference in
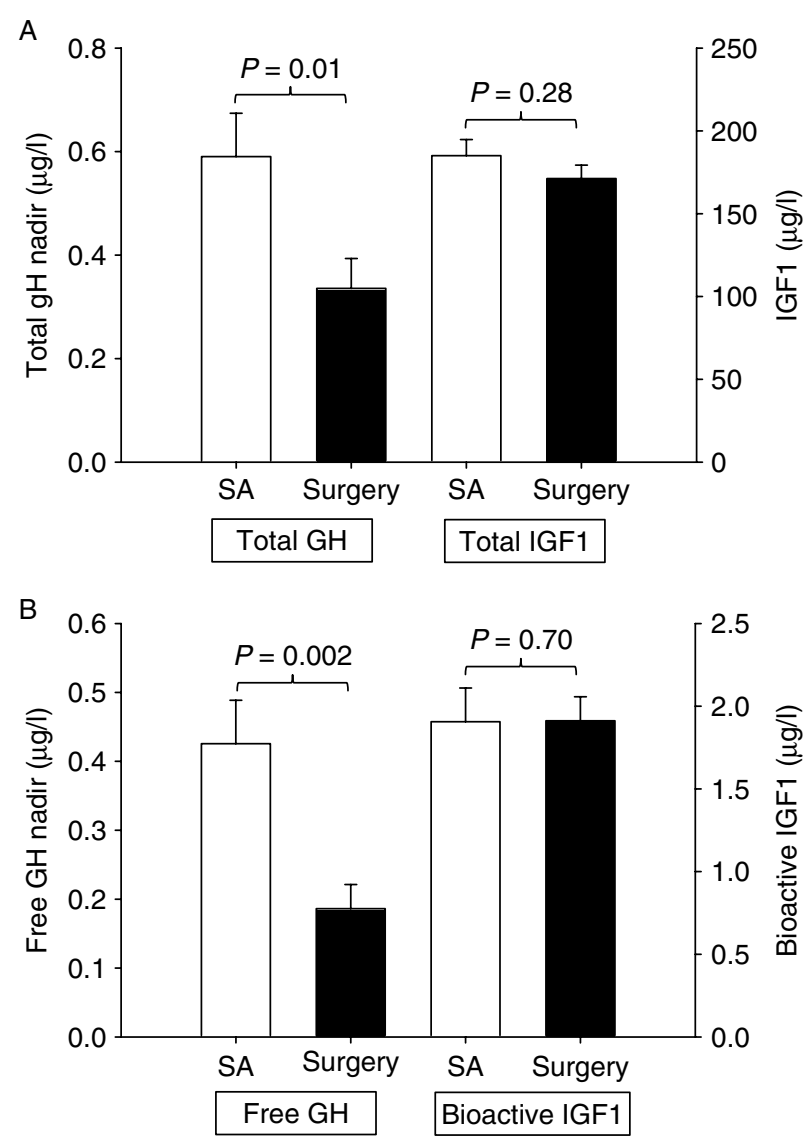

Figure 3 (A) Total GH and total IGF1 levels (mean \pm S.E.M.) after somatostatin analog (SA) treatment (open bars) versus surgical treatment (black bars). (B) Corresponding levels of free $\mathrm{GH}$ and bioactive IGF1. 


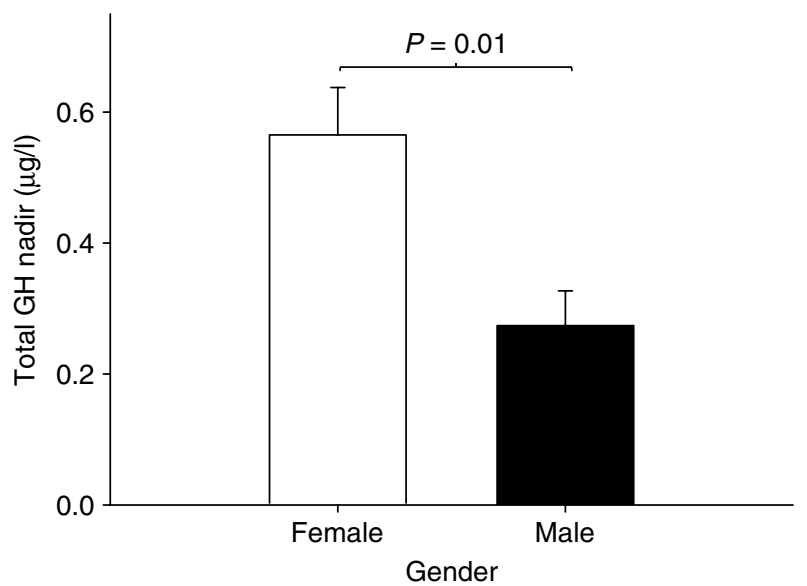

Figure 4 Total serum GH nadir levels (mean \pm S.E.M.) at the time of follow-up in female versus male patients.

adenoma size between the two groups, but this most likely reflects that the imaging data were limited and based on routine measurements. The outcome of surgery depends strongly on tumor size and localization $(1,20)$, and it is probable that the true prevalence of large and/or invasive adenomas was higher in the patients on SA treatment as compared with the patients treated with surgery only. Secondly, our inclusion criterion for all patients was achievement of a normalized serum IGF1 level at the time of follow-up. A normalized IGF1 level is an accepted definition of disease control (21), and IGF1 has also proven a reliable predictor of mortality in acromegaly $(6,22,23)$. But the patients represent a selected group since we did not include those with predefined 'normal' or 'safe' GH levels and elevated IGF1 levels. However, with these limitations in mind, we believe that our study has provided new and interesting information.

A high prevalence of elevated $\mathrm{GH}$ levels during the OGTT in the presence of normalized IGF1 levels during SA treatment has previously been observed (8). Other studies using spontaneous GH levels have recorded either the same pattern (24), a higher prevalence of elevated IGF1 levels (25), or no apparent discordance (26). This study, however, is the first to provide serum profiles of GH before and after an OGTT in combination with analysis of novel biomarkers.

Our observation regarding GH levels during SA treatment is in agreement with the data from Biermasz et al. (27), who recorded elevated non-pulsatile GH secretion in seven acromegalic patients with normalized IGF1 levels during SA treatment. That study was based on frequent blood sampling during $24 \mathrm{~h}$, which is not a feasible option in daily clinical practice. Our study indicates that information of a similar nature can be obtained with measurements during an oral glucose load. We consider this observation of potential clinical relevance and suggest that assessment of treatment
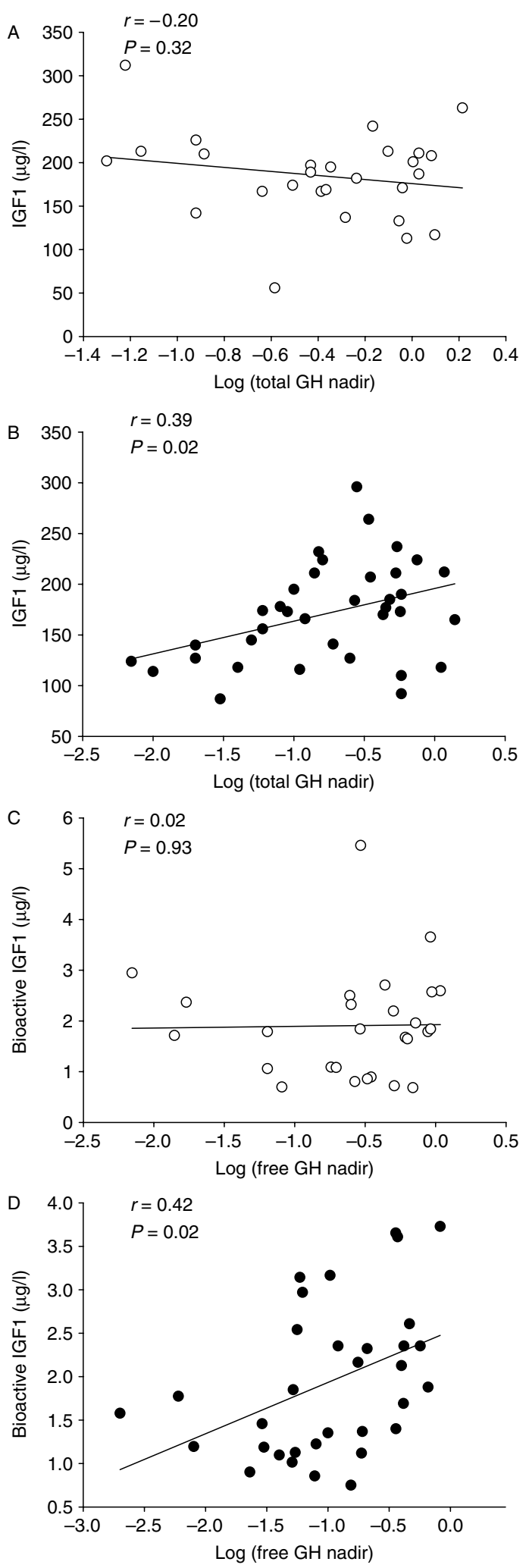

Figure 5 Correlations between IGF1 and GH after treatment. (A and C) Somatostatin analog $(S A)$ treatment. $(B$ and $D)$ Surgery alone. 
Table 4 Self-reported health status (see text). Data are presented as mean \pm s.E.M.

\begin{tabular}{|c|c|c|c|c|}
\hline & & SA treatment & Surgery & $P$ value \\
\hline \multicolumn{5}{|l|}{ EuroQoL: EQ-5D } \\
\hline Mobility & $1-3$ & $1.39 \pm 0.1$ & $1.19 \pm 0.1$ & 0.10 \\
\hline Self-care & $1-3$ & $1.13 \pm 0.1$ & $1.13 \pm 0.1$ & 0.96 \\
\hline Usual activities & $1-3$ & $1.39 \pm 0.1$ & $1.31 \pm 0.1$ & 0.56 \\
\hline Pain/discomfort & $1-3$ & $1.70 \pm 0.1$ & $1.47 \pm 0.1$ & 0.14 \\
\hline Anxiety/depression & $1-3$ & $1.26 \pm 0.1$ & $1.25 \pm 0.1$ & 0.78 \\
\hline $\begin{array}{l}\text { EQ-5D overall health status } \\
\text { Acrostudy: PASQ }\end{array}$ & \multicolumn{3}{|c|}{ Acrostudy: PASQ } & 0.29 \\
\hline Headache & $0-8$ & $2.20 \pm 0.5$ & $0.88 \pm 0.3$ & 0.01 \\
\hline Excessive sweating & $0-8$ & $2.05 \pm 0.6$ & $1.44 \pm 0.3$ & 0.46 \\
\hline Joint pain & $0-8$ & $3.70 \pm 0.6$ & $2.28 \pm 0.4$ & 0.049 \\
\hline Fatique & $0-8$ & $3.15 \pm 0.5$ & $2.47 \pm 0.4$ & 0.18 \\
\hline Soft tissue swelling & $0-8$ & $1.95 \pm 0.5$ & $1.16 \pm 0.3$ & 0.12 \\
\hline Numbness or tingling & $0-8$ & $2.15 \pm 0.5$ & $1.56 \pm 0.4$ & 0.29 \\
\hline PASQ total & $0-48$ & $15.20 \pm 2.5$ & $9.78 \pm 1.9$ & 0.04 \\
\hline PASQ overall health status & $0-10$ & $3.81 \pm 0.5$ & $2.47 \pm 0.4$ & 0.02 \\
\hline
\end{tabular}

EQ-5D: 1, no problems; 2, some problems; 3, extreme problems. EQ-5D VAS: 100 corresponds to the best imaginable health status and 0 to the worst imaginable. PASQ: 0 , no symptoms; 8 , invalidating symptoms. Overall PASQ: 0 , best possible health status; 10 , worst possible.

outcome includes measurement of GH during an OGTT also in SA-treated patients.

The possible mechanisms whereby SA treatment normalizes IGF1 levels despite relatively elevated GH levels are several. It is known that co-administration of octreotide reduces serum IGF1 levels in GH-substituted adult hypopituitary patients $(28,29)$, which supports a pituitary-independent effect of somatostatin that is not restricted to patients with acromegaly. Moreover, the suppressive effect of somatostatin on insulin secretion (13) may result in reduced hepatic IGF1 production, and hence lower serum IGF1 levels, in as much as insulin stimulates hepatic GHR synthesis and activity (30). Moreover, data from rodent studies show that somatostatin directly suppresses hepatic IGF1 production and possibly also the receptor-mediated clearance of GH (12), and a study in healthy human subjects indicates that somatostatin exerts $\mathrm{GH}$-antagonistic effects directly in skeletal muscle in vivo(31). It has also been suggested that somatostatin may antagonize the suppressive effect of oral glucose on GH secretion (8), and it is worth noting that the difference in GH levels in our study was mainly present during the OGTT. The elevation in GH relative to IGF1 observed in the SA group was even more pronounced when free GH levels were measured, which is compatible with the observation that GHBP levels were comparable in the two groups. At present, however, the precise role of free $\mathrm{GH}$ measurements in clinical practice remains to be defined, and the same applies to bioactive IGF1.

Somatostatin-induced suppression of portal insulin levels may also impact circulating IGF1 levels indirectly via effects on IGFBPs, particularly IGFBP1 (32). We did, however, not detect any differences in the levels of either IGFBPs or bioactive IGF1 in our two patient groups. SA treatment is associated with an increase in IGFBP1 levels, which may be a combination of a direct stimulatory effect of SA and suppression of insulin secretion (33). In addition, there are several lines of evidence to suggest that GH per se suppresses IGFBP1 $(34,35)$, and we have observed that surgically cured acromegalic patients exhibit supranormal IGFBP1 levels (36). So it could be argued that IGFBP1 levels are expected to increase after both types of therapy albeit perhaps via different mechanisms. Glucose tolerance was significantly impaired in the SA group, which is compatible with most albeit not all studies (37). The mechanism is readily explained by the inhibition of stimulated insulin secretion since insulin sensitivity has been shown to improve during SA treatment (38). We also recorded higher fasting levels of plasma glucose in the SA group, which contrasts with the average outcome of 31 trials (37).

Our observation of a positive correlation between serum levels of IGF1 and GH ( $\log _{10}$-transformed) in newly diagnosed acromegaly is in accordance with the literature (39), and it is interesting that this correlation is preserved after surgery and lost after SA treatment. It supports the notion that the effect of SA treatment is not restricted to suppression of $\mathrm{GH}$ secretion and as such differs from surgery alone.

It has previously been recorded that serum GH levels are higher in female as compared with male patients with acromegaly $(9,40-42)$, and our study demonstrates that this difference prevails during SA treatment. It is also interesting that the gender difference in our study was more pronounced when basal GH levels were compared. This gender-specific difference in GH levels is also observed in healthy subjects and seems to represent a relative GH resistance in females as compared with males. This notion is supported by the fact that $\mathrm{GH}$ dose requirements are higher in females as compared with male patients with adult GH deficiency (43). Several lines of evidence suggest that the elevated GH levels in 
females represent an increase in $\mathrm{GH}$ secretion to compensate for a suppressive effect of estrogen on hepatic IGF1 production $(44,45)$, but the genderspecific difference in patients with acromegaly is also reported in elderly subjects and is not fully accounted for by estrogen status (9). The observation made from that study, which did not include patients on medical treatment, was replicated in our population, and both dataset suggest that additional factors such as abdominal adiposity may contribute to the relative increase in GH levels in females as compared with males (46).

It is generally appreciated that health-related quality of life is impaired in acromegaly, and that this impairment is only partially restored following treatment (47-49). It was, however, unexpected that the disease-specific health status of SA-treated patients was significantly poorer as compared with patients treated only with surgery. It is important to emphasize that our study - due to its design - is unable to investigate if surgical treatment per se is superior to SA treatment as regards health status. It is likely that the two groups differed at the time of diagnosis in terms of disease severity, and that this may have contributed to the health status at the time of follow-up. Our results also do not question the usefulness of SA treatment. What our results do question is whether a normalized serum IGF1 level is a sufficient biomarker of disease activity especially during SA treatment. In this regard, our data support the observation made by Neggers et al. (50) that disease-specific quality of life improved significantly in the SA-treated patients following placebo-controlled co-treatment with pegvisomant despite unaltered and normalized serum IGF1 levels. Both studies suggest that serum IGF1 levels may not adequately reflect disease activity during SA treatment. To test this hypothesis, a randomized study in the SA-treated patients is required comparing the impact of targeting either 'safe' GH levels or normalized IGF1 levels on disease-specific health status. Such a study is feasible and would be relevant.

In conclusion, this study reports that achievement of normal IGF1 levels in patients with acromegaly during SA treatment is accompanied by relatively elevated nadir GH levels as compared with patients who achieve normal IGF1 levels after surgery alone. This was associated with a poorer disease-specific health status in the SA group. The underlying mechanisms for this discordance remain to be clarified, but we hypothesize that SA treatment not only reduces GH secretion from the pituitary tumor or its remnant, but also exerts a specific suppressive effect on hepatic IGF1 production. The latter effect of SA treatment may therefore result in biochemical normalization - as defined by serum IGF1 despite continued disease activity induced by circulating GH. This hypothesis should be tested in a randomized trial, but in the mean time, we suggest that assessment of treatment outcome in the SA-treated patients should include frequent measurements of serum GH during an OGTT in addition to a single IGF1 measurement.

\section{Declaration of interest}

J O L Jørgensen has received lecture fees and unrestricted research grants from Pfizer, Novartis, and Ipsen.

\section{Funding}

This research did not receive any specific grant from any funding agency in the public, commercial or not-for-profit sector.

\section{References}

1 Swearingen B, Barker FG II, Katznelson L, Biller BM, Grinspoon S, Klibanski A, Moayeri N, Black PM \& Zervas NT. Long-term mortality after transsphenoidal surgery and adjunctive therapy for acromegaly. Journal of Clinical Endocrinology and Metabolism 1998 83 3419-3426. (doi:10.1210/jc.83.10.3419)

2 Ch'ng LJ, Sandler LM, Kraenzlin ME, Burrin JM, Joplin GF \& Bloom SR. Long term treatment of acromegaly with a long acting analogue of somatostatin. BMJ 1985290 284-285. (doi:10. 1136/bmj.290.6464.284-a)

3 Chanson P, Borson-Chazot F, Kuhn JM, Blumberg J. Maisonobe P \& Delemer B. Control of IGF-I levels with titrated dosing of lanreotide Autogel over 48 weeks in patients with acromegaly. Clinical Endocrinology 200869 299-305. (doi:10.1111/j.1365-2265. 2008.03208.x)

4 Maison P, Tropeano AI, Macquin-Mavier I, Giustina A \& Chanson P. Impact of somatostatin analogs on the heart in acromegaly: a meta analysis. Journal of Clinical Endocrinology and Metabolism 200792 1743-1747. (doi:10.1210/jc.2006-2547)

5 Dekkers OM, Biermasz NR, Pereira AM, Romijn JA \& Vandenbroucke JP. Mortality in acromegaly: a meta analysis. Journal of Clinical Endocrinology and Metabolism 200893 61-67. (doi:10.1210/jc.2007-1191)

6 Holdaway IM, Bolland MJ \& Gamble GD. A meta-analysis of the effect of lowering serum levels of GH and IGF-I on mortality in acromegaly. European Journal of Endocrinology 2008159 89-95. (doi:10.1530/EJE-08-0267)

7 Freda PU. Current concepts in the biochemical assessment of the patient with acromegaly. Growth Hormone and IGF Research 2003 13 171-184. (doi:10.1016/S1096-6374(03)00029-7)

8 Carmichael JD, Bonert VS, Mirocha JM \& Melmed S. The utility of oral glucose tolerance testing for diagnosis and assessment of treatment outcomes in 166 patients with acromegaly. Journal of Clinical Endocrinology and Metabolism 2009 94 523-527. (doi:10.1210/jc.2008-1371)

9 Parkinson C, Ryder WD \& Trainer PJ. The relationship between serum GH and serum IGF-I in acromegaly is gender-specific. Journal of Clinical Endocrinology and Metabolism $2001 \mathbf{8 6}$ 5240-5244. (doi:10.1210/jc.86.11.5240)

10 Freda PU, Nuruzzaman AT, Reyes CM, Sundeen RE \& Post KD. Significance of "abnormal" nadir growth hormone levels after oral glucose in postoperative patients with acromegaly in remission with normal insulin-like growth factor-I levels. Journal of Clinical Endocrinology and Metabolism 200489 495-500. (doi:10.1210/ jc.2003-031316)

11 Dimaraki EV, Jaffe CA, DeMott-Friberg R, Chandler WF \& Barkan AL. Acromegaly with apparently normal GH secretion: implications for diagnosis and follow-up. Journal of Clinical Endocrinology and Metabolism 200287 3537-3542. (doi:10. $1210 /$ jc.87.8.3537) 
12 Murray RD, Kim K, Ren SG, Chelly M, Umehara Y \& Melmed S. Central and peripheral actions of somatostatin on the growth hormone-IGF-I axis. Journal of Clinical Investigation 2004114 349-356. (doi:10.1172/JCI19933)

13 Alberti KG, Christensen NJ, Christensen SE, Hansen AP, Iversen J, Lundbaek K, Seyer-Hansen K \& Orskov H. Inhibition of insulin secretion by somatostatin. Lancet 19732 1299-1301. (doi:10. 1016/S0140-6736(73)92873-0)

14 Wurzburger MI, Prelevic GM, Sonksen PH, Balint-Peric LA \& Wheeler M. The effect of recombinant human growth hormone on regulation of growth hormone secretion and blood glucose in insulin-dependent diabetes. Journal of Clinical Endocrinology and Metabolism 199377 267-272. (doi:10.1210/jc.77.1.267)

15 Frystyk J, Dinesen B \& Ørskov H. Non-competitive time-resolved immunofluorometric assays for determination of human insulinlike growth factor I and II. Growth Regulation 19955 169-176.

16 Chen JW, Ledet T, Ørskov H, Jessen N, Lund S, Whittaker J, De Meyts P, Larsen MB, Christiansen JS \& Frystyk J. A highly sensitive and specific assay for determination of IGF-I bioactivity in human serum. American Journal of Physiology. Endocrinology and Metabolism 2003284 E1149-E1155. (doi:10.1152/ajpendo. 00410.2002)

17 Jeyaratnaganthan N, Grønbaek H, Holland-Fischer P, Espelund U, Chen JW, Flyvbjerg A, Vilstrup H \& Frystyk J. Ascites from patients with alcoholic liver cirrhosis contains higher IGF-I bioactivity than serum. Clinical Endocrinology 201072 625-632. (doi:10. 1111/j.1365-2265.2009.03707.x)

18 Frystyk J, Andreasen CM \& Fisker S. Determination of free growth hormone. Journal of Clinical Endocrinology and Metabolism 200893 3008-3014. (doi:10.1210/jc.2008-0375)

19 Fisker S, Frystyk J, Skriver L, Vestbo E, Ho KK \& Orskov H. A simple, rapid immunometric assay for determination of functional and growth hormone-occupied growth hormone-binding protein in human serum. European Journal of Clinical Investigation 199626 779-785. (doi:10.1046/j.1365-2362.1996.2010558.x)

20 Abosch A, Tyrrell JB, Lamborn KR, Hannegan LT, Applebury CB \& Wilson CB. Transsphenoidal microsurgery for growth hormonesecreting pituitary adenomas: initial outcome and long-term results. Journal of Clinical Endocrinology and Metabolism $1998 \mathbf{8 3}$ 3411-3418. (doi:10.1210/jc.83.10.3411)

21 Freda PU, Post KD, Powell JS \& Wardlaw SL. Evaluation of disease status with sensitive measures of growth hormone secretion in 60 postoperative patients with acromegaly. Journal of Clinical Endocrinology and Metabolism $1998 \mathbf{8 3}$ 3808-3816. (doi:10. $1210 /$ jc. 83.11 .3808$)$

22 Holdaway IM, Rajasoorya RC \& Gamble GD. Factors influencing mortality in acromegaly. Journal of Clinical Endocrinology and Metabolism 200489 667-674. (doi:10.1210/jc.2003-031199)

23 Biermasz NR, Dekker FW, Pereira AM, van Thiel SW, Schutte PJ. van Dulken H, Romijn JA \& Roelfsema F. Determinants of survival in treated acromegaly in a single center: predictive value of serial insulin-like growth factor I measurements. Journal of Clinical Endocrinology and Metabolism 200489 2789-2796. (doi:10. 1210/jc.2003-032041)

24 Cozzi R, Attanasio R, Grottoli S, Pagani G, Loli P, Gasco V, Pedroncelli AM, Montini M \& Ghigo E. Treatment of acromegaly with SS analogues: should GH and IGF-I target levels be lowered to assert a tight control of the disease? Journal of Endocrinological Investigation 200427 1040-1047.

25 Machado EO, Taboada GF, Neto LV, vanHaute FR, Corrêa LL, Balarini GA, Shrank Y, Goulart M \& Gadelha MR. Prevalence of discordant GH and IGF-I levels in acromegalics at diagnosis, after surgical treatment and during treatment with octreotide LAR. Growth Hormone \& IGF Research 200818 389-393. (doi:10. 1016/j.ghir.2008.02.001)

26 Ronchi CL, Varca V, Beck-Peccoz P, Orsi E, Donadio F, Baccarelli A, Giavoli C, Ferrante E, Lania A, Spada A \& Arosio M. Comparison between six-year therapy with long-acting somatostatin analogs and successful surgery in acromegaly: effects on cardiovascular risk factors. Journal of Clinical Endocrinology and Metabolism 2006 91 121-128. (doi:10.1210/jc.2005-1704)
27 Biermasz NR, Pereira AM, Frolich M, Romijn JA, Veldhuis JD \& Roelfsema F. Octreotide represses secretory-burst mass and nonpulsatile secretion but does not restore event frequency or orderly GH secretion in acromegaly. American Journal of Physiology. Endocrinology and Metabolism 2004286 E25-E30. (doi:10.1152/ ajpendo.00230.2003)

28 Laursen T, Moller J, Fisker S, Jorgensen JO \& Christiansen JS. Effects of a 7-day continuous infusion of octreotide on circulating levels of growth factors and binding proteins in growth hormone (GH)treated GH-deficient patients. Growth Hormone \& IGF Research 19999 451-457. (doi:10.1054/ghir.1999.0131)

29 Pokrajac A, Frystyk J, Flyvbjerg A \& Trainer PJ. Pituitary-independent effect of octreotide on IGF1 generation. European Journal of Endocrinology 2009160 543-548. (doi:10.1530/EJE-08-0822)

30 Leung KC, Doyle N, Ballesteros M, Waters MJ \& Ho KK. Insulin regulation of human hepatic growth hormone receptors: divergent effects on biosynthesis and surface translocation. Journal of Clinical Endocrinology and Metabolism 200085 4712-4720. (doi:10. $1210 /$ jc. 85.12 .4712 )

31 Moller N, Bagger JP, Schmitz O, Jorgensen JO, Ovesen P, Moller J, Alberti KG \& Orskov H. Somatostatin enhances insulin-stimulated glucose uptake in the perfused human forearm. Journal of Clinical Endocrinology and Metabolism 199580 1789-1793. (doi:10. 1210/jc.80.6.1789)

32 Suikkari AM, Koivisto VA, Rutanen EM, Yki-Jarvinen H, Karonen SL \& Seppala M. Insulin regulates the serum levels of low molecular weight insulin-like growth factor-binding protein. Journal of Clinical Endocrinology and Metabolism $1988 \mathbf{6 6}$ 266-272. (doi:10.1210/jcem-66-2-266)

33 Ezzat S, Ren SG, Braunstein GD \& Melmed S. Octreotide stimulates insulin-like growth factor binding protein-1 (IGFBP-1) levels in acromegaly. Journal of Clinical Endocrinology and Metabolism 1991 73 441-443. (doi:10.1210/jcem-73-2-441)

34 Ono M, Chia DJ, Merino-Martinez R, Flores-Morales A, Unterman TG \& Rotwein P. Signal transducer and activator of transcription (Stat) 5b-mediated inhibition of insulin-like growth factor binding protein-1 gene transcription: a mechanism for repression of gene expression by growth hormone. Molecular Endocrinology 200721 1443-1457. (doi:10.1210/me.20060543)

35 Norrelund H, Fisker S, Vahl N, Borglum J, Richelsen B, Christiansen JS \& Jørgensen JO. Evidence supporting a direct suppressive effect of growth hormone on serum IGFBP-1 levels. Experimental studies in normal, obese and GH-deficient adults. Growth Hormone \& IGF Research 19999 52-60. (doi:10.1054/ ghir.1998.0087)

36 Jorgensen JO, Moller N, Moller J, Weeke J \& Blum WF. Insulin-like growth factors (IGF)-I and -II and IGF binding protein-1, -2, and -3 in patients with acromegaly before and after adenomectomy. Metabolism 199443 579-583. (doi:10.1016/0026-0495(94) 90199-6)

37 Mazziotti G, Floriani I, Bonadonna S, Torri V, Chanson P \& Giustina A. Effects of somatostatin analogs on glucose homeostasis: a metaanalysis of acromegaly studies. Journal of Clinical Endocrinology and Metabolism 200994 1500-1508. (doi:10.1210/jc.2008-2332)

38 Baldelli R, Battista C, Leonetti F, Ghiggi MR, Ribaudo MC, Paoloni A, D’Amico E, Ferretti E, Baratta R, Liuzzi A, Trischitta V \& Tamburrano G. Glucose homeostasis in acromegaly: effects of long-acting somatostatin analogues treatment. Clinical Endocrinology 200359 492-499. (doi:10.1046/j.1365-2265. 2003.01876.x)

39 Barkan AL, Beitins IZ \& Kelch RP. Plasma insulin-like growth factor-I/somatomedin-C in acromegaly: correlation with the degree of growth hormone hypersecretion. Journal of Clinical Endocrinology and Metabolism 198867 69-73. (doi:10.1210/ jcem-67-1-69)

40 Alexopoulou O, Bex M, Abs R, T'sjoen G, Velkeniers B \& Maiter D. Divergence between growth hormone and insulin-like growth 
factor-I concentrations in the follow-up of acromegaly. Journal of Clinical Endocrinology and Metabolism 200893 1324-1330. (doi:10.1210/jc.2007-2104)

41 Arafat AM, Möhlig M, Weickert MO, Perschel FH, Purschwitz J, Spranger J, Strasburger CJ, Schöfl C \& Pfeiffer AF. Growth hormone response during oral glucose tolerance test: the impact of assay method on the estimation of reference values in patients with acromegaly and in healthy controls, and the role of gender, age, and body mass index. Journal of Clinical Endocrinology and Metabolism 200893 1254-1262. (doi:10.1210/jc.2007-2084)

42 Ho KY, Evans WS, Blizzard RM, Veldhuis JD, Merriam GR, Samojlik E, Furlanetto R, Rogol AD, Kaiser DL \& Thorner MO. Effects of sex and age on the 24-hour profile of growth hormone secretion in man: importance of endogenous estradiol concentrations. Journal of Clinical Endocrinology and Metabolism 198764 51-58. (doi:10.1210/jcem-64-1-51)

43 Burman P, Johansson AG, Siegbahn A, Vessby B \& Karlsson FA. Growth hormone (GH)-deficient men are more responsive to $\mathrm{GH}$ replacement therapy than women. Journal of Clinical Endocrinology and Metabolism 199782 550-555. (doi:10.1210/jc.82.2.550)

44 Leung KC, Doyle N, Ballesteros M, Sjogren K, Watts CK, Low TH, Leong GM, Ross RJ \& Ho KK. Estrogen inhibits GH signaling by suppressing GH-induced JAK2 phosphorylation, an effect mediated by SOCS-2. PNAS 2003100 1016-1021. (doi:10.1073/pnas. $0337600100)$

45 Christiansen JJ, Fisker S, Gravholt CH, Bennett P, Svenstrup B, Andersen M, Feldt-Rasmussen U, Christiansen JS \& Jørgensen JOL. Discontinuation of estrogen replacement therapy in GH-treated hypopituitary women alters androgen status and IGF-I. European Journal of Endocrinology 2005152 719-726. (doi:10.1530/eje.1. 01898)

46 Vahl N, Jorgensen JO, Skjaerbaek C, Veldhuis JD, Orskov H \& Christiansen JS. Abdominal adiposity rather than age and sex predicts mass and regularity of GH secretion in healthy adults. American Journal of Physiology 1997272 E1108-E1116.

47 Webb SM. Quality of life in acromegaly. Neuroendocrinology 2006 83 224-229. (doi:10.1159/000095532)

48 Biermasz NR, van Thiel SW, Pereira AM, Hoftijzer HC, van Hemert AM, Smit JW, Romijn JA \& Roelfsema F. Decreased quality of life in patients with acromegaly despite long-term cure of growth hormone excess. Journal of Clinical Endocrinology and Metabolism 200489 5369-5376. (doi:10.1210/jc.2004-0669) 49 Kauppinen-Mäkelin R, Sane T, Sintonen H, Markkanen H, Välimäki MJ, Löyttyniemi E, Niskanen L, Reunanen A \& Stenman UH. Quality of life in treated patients with acromegaly. Journal of Clinical Endocrinology and Metabolism $2006 \mathbf{9 1}$ 3891-3896. (doi:10.1210/jc.2006-0676)

50 Neggers SJ, van Aken MO, de Herder WW, Feelders RA, Janssen JA, Badia X, Webb SM \& van der Lely AJ. Quality of life in acromegalic patients during long-term somatostatin analog treatment with and without pegvisomant. Journal of Clinical Endocrinology and Metabolism 200893 3853-3859. (doi:10.1210/jc.2008-0669)

Received 26 August 2010

Accepted 2 September 2010 